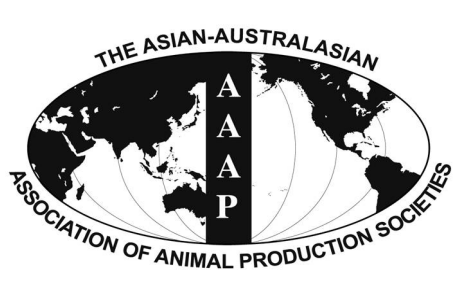

\begin{tabular}{c} 
Open Access \\
Asian Australas. J. Anim. Sci. \\
Vol. 29, No. 2 : 195-203 February 2016 \\
http://dx.doi.org/10.5713/ajas.15.0264 \\
\hline www.ajas.info \\
pISSN 101 1-2367 elSSN 1976-5517
\end{tabular}

\title{
Effects of Rice Bran, Flax Seed, and Sunflower Seed on Growth Performance, Carcass Characteristics, Fatty Acid Composition, Free Amino Acid and Peptide Contents, and Sensory Evaluations of Native Korean Cattle (Hanwoo)
}

\author{
Chang Bon Choi*, Hana Kwon, Sung Il Kim², Un Mok Yang ${ }^{3}$, Ju Hwan Lee ${ }^{3}$, and Eun Kyu Park ${ }^{3}$ \\ School of Biotechnology, Yeungnam University, Gyeongsan 38541, Korea
}

\begin{abstract}
This study was conducted to evaluate the effect of dietary supplementation with rice bran, flax seed, or sunflower seed to finishing native Korean cattle (Hanwoo) on growth performances, carcass characteristics, fatty acid composition, free amino acid and peptide contents, and sensory evaluations of Longissimus muscle (LM). A total of 39 Hanwoo steers (average age of 22.2 mo and average body weight (BW) of $552.2 \mathrm{~kg}$ ) were randomly divided into Control, rice bran (RB), flax seed (FS), or Sunflower seed (SS) groups. The steers were group fed for $273 \mathrm{~d}$ until they reached an average age of 31.2 mo. Final BW was 768.2, 785.8, 786.2, and 789.0 $\mathrm{kg}$, and average daily gain was $0.79,0.85,0.82$, and $0.84 \mathrm{~kg}$ for the Control, RS, FS, and SS groups, respectively (p>0.05). Fat thickness of the FS group $(19.8 \mathrm{~mm})$ was greater $(\mathrm{p}<0.05)$ than that of the other groups. Final yield grade converted into numerical values was 2.0 for the RB group, 1.7 for the Control and SS groups, and 1.4 for the FS group. Marbling degrees for the Control, SS, RB, and FS groups were 5.3, 5.1, 4.7, and 4.6, respectively. Percentages of palmitic acid $\left(\mathrm{C}_{16: 0}\right)$, stearic acid $\left(\mathrm{C}_{18: 0}\right)$, and arachidic acid $\left(\mathrm{C}_{20: 0}\right)$ in the $\mathrm{LM}$ were not different among the groups. Palmitoleic $\left(\mathrm{C}_{16: 1}\right)$ acid was higher $(\mathrm{p}<0.05)$ in the SS group. The concentration of oleic acid was highest $(p<0.05)$ in the Control group $(47.73 \%)$. The level of linolenic acid $\left(\mathrm{C}_{18: 3}\right)$ was 2.3 times higher $(\mathrm{p}<0.05)$ in the FS group compared to the other groups. Methionine concentration was $(\mathrm{p}<0.05)$ higher in FS $(1.7 \mathrm{mg} / 100 \mathrm{~g})$ and SS $(1.2 \mathrm{mg} / 100 \mathrm{~g}) \mathrm{steers}$ than in the Control or RB groups. Glutamic acid and $\alpha$-aminoadipic acid $(\alpha$-AAA) contents were $(p<0.05)$ higher in the FS group compared to the other groups. LM from the FS group had numerically higher $(p>0.05)$ scores for flavor, umami, and overall palatability in sensory evaluations. In conclusion, supplementation of flax seed to diets of finishing Hanwoo steers improved sensory evaluations which might have been caused by increases in flavor related amino acids such as methionine, glutamic acid and $\alpha$-AAA and peptides, anserine and carnosine, and their complex reactions. (Key Words: Flax Seed, Methionine, Glutamic Acid, $\alpha$-Aminoadipic Acid, Sensory Evaluations, Hanwoo)
\end{abstract}

\section{INTRODUCTION}

For the last four decades, scientists have been trying to increase omega-3 polyunsaturated fatty acids (PUFAs) in

\footnotetext{
* Corresponding Author: Chang Bon Choi. Tel: +82-53-810-3023, Fax: +82-53-810-4769, E-mail: cbchoi@yu.ac.kr

${ }^{1}$ Department of Food and Nutrition, Yeungnam University, Gyeongsan 38541, Korea.

${ }^{2}$ Department of Animal Science, Gyeongbuk Provincial College, Yecheon 36830, Korea.

${ }^{3}$ Woosung Feed Co., Ltd., Daejeon 34379, Korea.

Submitted Mar. 25, 2015; Revised May 20, 2015; Accepted Jun. 17, 2015
}

meat because saturated fatty acids (SFAs) are associated with many human disorders although meat is an important food source. Feeding cattle with high-grain diets, supplementation of linseed or linseed oil into diets, or utilization of protected fat that is not degraded in the rumen could be included in these efforts. Recent reports indicate that monounsaturated fatty acid (MUFA) in human diets lowers blood cholesterol and reduces the risk for metabolic disorders (Whetsell et al., 2003), improves blood pressure, and increases insulin sensitivity (Gillingham et al., 2011). Fatty acids in beef are not only related with human health but also affect beef quality. Flavors attributed to volatile 
flavor components in cooked meat are the most important factors for the sensory quality of meat. Volatile components are derived from thermally induced reactions occurring during heating via four pathways: i) Maillard reaction of amino acid or peptides with reducing sugars, ii) lipid oxidation, iii) interaction between Maillard reaction products with lipid-oxidized products, and iv) vitamin degradation. Efforts to produce flavorful beef have been undertaken since the most important motivators influencing consumers' beef purchases are i) taste, ii) price, and iii) product consistency. To date, efforts to manage beef palatability attributes at the producer-level have focused specifically on pre-harvest management of beef tenderness. Lipids and produced volatile compounds during cooking are major contributors to the odor and flavor of meat. Thus, cattle production systems that encourage the deposition of intramuscular fat are fundamentally important for developing desirable beef flavor characteristics (Ritchie, 2005). Since the South Korean beef market was opened in 1992, scientists and farmers have worked to improve the competitiveness of native Korean cattle (Hanwoo) to imported beef. The main feeding strategy of Korean beef cattle industry practices include feeding high amount of concentrates and rice straw as the sole roughage source. This strategy is quite different from those of other countries such as the United States, Latin American nations (Brazil, Argentina, and Uruguay), Australia, and New Zealand that have implemented roughage-based feeding programs. The unique feeding program for Hanwoo in Korea has resulted in highly marbled beef with particularly high percentages of oleic acid $(\sim 50 \%)$, a major MUFA. Additionally, the MUFA/SFA ratios of Hanwoo, corn-fed Angus, and hay-fed Angus beef were found to be 1.28, 0.86, and 0.66, respectively (Smith et al., 2006). A high proportion of MUFAs including oleic acid can help to prevent human cardiovascular diseases (Kris-Etherton et al., 1999), elevated blood pressure (Rasmussen et al., 2006), and diabetes mellitus (Due et al., 2008). Furthermore, MUFAs are also acknowledged to have positive effects on beef palatability. High proportions of oleic acid in beef decrease the melting point of lipids extracted from sirloin produced by Hanwoo steers (Kim et al., 2013b). According to a panel test, Hanwoo beef with high MUFA percentages also has high palatability scores compared to imported beef with relatively low MUFA concentrations (Kim et al., 2011). In addition, information provided by previous studies implies that beef produced with a concentrate-based feeding system has high scores for tenderness, juiciness, umami, and overall palatability. Based on these data, this study was realized to determine whether feeding finishing diet of Hanwoo steers supplemented with rice bran, flax seed, or sunflower seed would affect animal performances and carcass characteristics. Additionally, the fatty acid composition, free amino acid and peptide contents, and sensory evaluation results of longissimus muscle (LM) were also assessed.

\section{MATERIALS AND METHODS}

\section{Experimental animals and diets}

A total of 39 Hanwoo steers (average age of $22.2 \pm 2.3$ mo and average body weight [BW] of $552.2 \pm 32.8 \mathrm{~kg}$ ) in local farm were divided into Control (10 animals), rice bran (RB, 10 animals), flax seed (FS, 9 animals), or sunflower seed (SS, 10 animals).

The steers were group fed and housed in groups of four or five animals in $5.0 \times 10.0 \mathrm{~m}$ pens (a total of eight pens). The cattle were fed for $273 \mathrm{~d}$ until they reached an average age of $31.2 \pm 2.3$ mo. Commercial concentrates (The Hanwoomaru Finishing, Woosung Feed Co., Ltd., Daejeon, Korea) for finishing Hanwoo steers were fed to the Control group (Table 1) and used as a basal concentrate for the RB, $\mathrm{FS}$, and SS groups. For the concentrates given to the RB, FS, and SS group, 5\% of the Control concentrate was replaced with $\mathrm{RB}, \mathrm{FS}$, and $\mathrm{SS}$, respectively. Ten $\mathrm{kg}$ of concentrates per $d$ were given to each animal until the end of the experiment. The steers had free access to rice to rice straw as the sole roughage source and water ad libitum. Chemical composition of the concentrates for each treatment group is shown in Table 2.

Table 1. Ingredients of commercial concentrate for finishing Hanwoo steers (DM basis)

\begin{tabular}{lc}
\hline Ingredients & $\%$ \\
\hline Corn & 25.0 \\
Wheat & 22.0 \\
Barley & 10.0 \\
Wheat bran & 5.5 \\
Rice bran & 5.0 \\
Corn gluten feed & 5.0 \\
Coconut oil & 5.0 \\
Palm kernal & 5.0 \\
Canola & 3.0 \\
DDGS & 3.0 \\
Cottonseed whole & 3.0 \\
Cane molasses & 3.0 \\
Limestone & 1.5 \\
Salt & 0.8 \\
Sodium bicarbonate & 0.7 \\
Magnesium oxide & 0.3 \\
Mineral premix & 0.2 \\
Vitamin premix & 0.1 \\
Others* & 1.9 \\
\hline
\end{tabular}

DM, dry matter; DDGS, distiller's dried grains with solubles.

* Pre-/probiotics, organic minerals, buffers, etc. 
Table 2. Chemical composition of concentrates fed to the finishing Hanwoo steers

\begin{tabular}{|c|c|c|c|c|}
\hline$\overline{\text { Item }}$ & Control & $\mathrm{RB}$ & FS & SS \\
\hline & \multicolumn{4}{|c|}{ 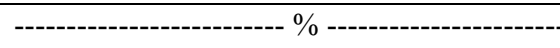 } \\
\hline Dry matter & 87.50 & 87.53 & 87.73 & 87.68 \\
\hline Crude protein & 12.00 & 12.10 & 12.35 & 12.30 \\
\hline Ether extract & 4.15 & 4.86 & 5.92 & 5.94 \\
\hline Crude fiber & 6.21 & 6.32 & 6.62 & 6.85 \\
\hline Crude ash & 7.12 & 7.20 & 6.95 & 6.96 \\
\hline NFE & 58.02 & 57.06 & 55.89 & 55.62 \\
\hline NFC & 43.23 & 42.17 & 41.07 & 41.07 \\
\hline $\mathrm{Ca}$ & 0.90 & 0.86 & 0.86 & 0.87 \\
\hline$P$ & 0.45 & 0.53 & 0.46 & 0.46 \\
\hline $\mathrm{ADF}$ & 9.00 & 9.09 & 9.80 & 10.28 \\
\hline NDF & 21.00 & 21.21 & 21.44 & 21.40 \\
\hline TDN & 74.00 & 74.51 & 75.70 & 75.65 \\
\hline
\end{tabular}

$\mathrm{RB}$, rice bran; FS, flax seed; SS, sunflower seed; NFE, nitrogen-free extract; NFC, non-fibrous carbohydrate; ADF, acid detergent fiber; NDF, neutral detergent fiber; TDN, total digestible nutrients.

\section{Carcass evaluation}

At the end of the experiment, all steers were transported to a local abattoir (Gyeongsan, Korea) and slaughtered by exsanguination after stunning. After chilling the carcasses for $24 \mathrm{~h}$ at $4^{\circ} \mathrm{C}$, cold carcass weight, indices (marbling degree, LM area, fat thickness, meat color, fat color, texture, and maturity at the 13th rib) for yield grade and quality grade of the carcasses were measured according to the Korean Beef Carcass Grading Standard (2014).

\section{Total lipid extraction}

Samples of LM taken between the 12th and 13th ribs were removed from each carcass and transported to the laboratory while kept at $4^{\circ} \mathrm{C}$. After trimming the subcutaneous fat, the samples were homogenized and stored in a freezer at $-80^{\circ} \mathrm{C}$ until analysis. Total lipids were extracted from the beef samples using the modified method by Folch et al. (1957). Approximately $5 \mathrm{~g}$ of muscle tissue was homogenized (Polytron PT2100, Kinematica Inc., Bohemia, NY, USA) with $5 \mathrm{~mL}$ of chloroform:methanol (2:1, vol:vol) solution and incubated at room temperature for $30 \mathrm{~min}$. The homogenate was filtered through Whatman GF/C filters (Whatman Ltd., Maidstone, UK) and rinsed with an additional $10 \mathrm{~mL}$ of chloroform:methanol solution. The extracted lipid was combined with $8 \mathrm{~mL}$ of $0.74 \% \mathrm{KCl}$ and stirred for $1 \mathrm{~min}$. After the phases separated, the lipid layer was transferred to 20 -mL scintillation vials (Wheaton, Millville, NJ, USA) and the solvents were evaporated by heating (C-WBE, Changshin Science, Seoul, Korea) at $60^{\circ} \mathrm{C}$ under nitrogen.

\section{Fatty acid composition analysis}

The lipids extracted from LM were methylated according to the method by Lepage and Roy (1986) and the fatty acid composition was analyzed using gas chromatography. Approximately $200 \mu \mathrm{L}$ of each lipid extract were converted into fatty acid methyl esters by adding $2 \mathrm{~mL}$ methanol:benzene ( $4: 1$, vol:vol) solution and $200 \mu \mathrm{L}$ of acetyl chloride, and heated for $40 \mathrm{~min}$ at $100^{\circ} \mathrm{C}$ on a heating block (Lab \& Tools, Anyang, Korea). One mL isooctane (Sigma-Aldrich, Saint Louis, MO, USA) and 8 $\mathrm{mL}$ of $6 \%$ potassium carbonate (Junsei, Tokyo, Japan) were added, and the solution was centrifuged (1580R, Labogene, Daejeon, Korea) for $10 \mathrm{~min}$ at $500 \times \mathrm{g}$. One (1) $\mu \mathrm{L}$ of the supernatant was subjected to analysis with a gas chromatography (Clarus 500; Perkin Elmer, Shelton, CT, USA) equipped with a fused column SP 2560 (100 m in length, $0.25 \mathrm{~mm}$ in diameter, $0.2 \mathrm{um}$ film thickness) using nitrogen as the carrier gas (flow rate of $1.0 \mathrm{~mL} / \mathrm{min}$ ). The initial oven temperature was $210^{\circ} \mathrm{C}$; the injector and detector temperatures were $240^{\circ} \mathrm{C}$ and $250^{\circ} \mathrm{C}$, respectively.

\section{Measurement of free amino acid contents}

Free amino acid contents in the samples were analyzed as previously described by Henderson et al. (2000). Ten grams of LM sample were dissolved in $200 \mathrm{~mL}$ of $80 \%$ ethanol and stored at room temperature for 12 hours. The solution was filtered (Whatman filter paper No. 2, GE Healthcare Bio-Sciences Corp., Piscataway, NJ, USA). The filtrate was concentrated on an evaporator (Eyela Rotary evaporator N-1100, Tokyo Rikakikai, Co., Tokyo, Japan) at $45^{\circ} \mathrm{C}$ and dissolved in $40 \mathrm{~mL}$ of distilled water. Infranatant separated by funnel after adding ethyl ether $(20 \mathrm{~mL}$; SigmaAldrich, Saint Louis, MO, USA) was evaporated. The residue was dissolved in $20 \mathrm{~mL}$ of $0.2 \mathrm{M}$ citrate buffer and filtered through $0.45 \mu \mathrm{m}$ syringe filter (Toyo Roshi Kaisha, Ltd., Tokyo, Japan) and the free amino acids were analyzed with HPLC (L-8900, Hitachi, Tokyo, Japan). Cation exchange resin $(4.6 \mathrm{~mm} \times 60 \mathrm{~mm})$ was used as a column, Lithium Citrate Buffer solution $(0.35 \mathrm{~mL} / \mathrm{min})$ was used as a mobile phase $A$, and Ninhydrin reagents $(0.3 \mathrm{~mL} / \mathrm{min})$ solution was used as a mobile phase B. Free amino acid mixture standard solution (Wako Pure Chemical Co., Osaka, Japan) was used as derivatives.

\section{Sensory evaluation}

Ten panelists were trained according to the modified methods of the National Live Stock and Meat Board (1995). LM samples used for sensory evaluation had the same quality grade $\left(1^{++}\right.$grade according to the Korean Beef Carcass Grading Standard). The samples were cut into portions $2 \times 2.5 \times 1 \mathrm{~cm}(\mathrm{~L} \times \mathrm{W} \times \mathrm{D})$ in size and cooked at $220^{\circ} \mathrm{C}$ for $60 \mathrm{~s}$ on the front and $90 \mathrm{~s}$ on the back. The cooked samples were immediately served to the panelists. The tenderness, juiciness, flavor, umami, oiliness, and overall palatability (1; extremely tough, dry, not flavorful, bland, dry, or unacceptable to 8; extremely tender, juicy, flavorful, 
intense, oily, or acceptable) of the steaks were evaluated.

\section{Statistical analysis}

Data were analyzed with a one-way analysis of variance using SPSS (2011) Ver. 19.0 (SPSS Inc., Chicago, IL, USA). The steers were randomly assigned into pens and pens served as the experimental unit for growth performance, carcass characteristics, carcass grade, fatty acid composition, free amino acid contents, and sensory evaluation data. Significances were tested at 5\% level and Tukey's multiple range test was used to compare results among the treatment groups.

\section{RESULTS AND DISCUSSION}

\section{Growth performance}

Final BW of the Control, RB, FS, and SS groups was $768.2 \pm 36.2,785.8 \pm 48.2,786.2 \pm 18.4$, and $789.0 \pm 73.3 \mathrm{~kg}$, respectively. The mean initial $\mathrm{BW}$ of all the experimental Hanwoo steers was $552.2 \pm 32.8 \mathrm{~kg}$. The average daily gain (ADG) was $0.79 \pm 0.1,0.85 \pm 0.1,0.82 \pm 0.1$, and $0.84 \pm 0.2 \mathrm{~kg}$ for the Control, RB, FS, and SS steers, respectively. No differences $(\mathrm{p}>0.05)$ were observed among groups (Table 3 ).
Forster et al. (1993) compared the growth performance of steers given diets supplemented with grazing tall fescue, clover, and Bermuda grass hay with either low or high levels of corn or rice bran, and found that the rate of BW gain for rice bran-supplemented calves was greater than the nonsupplemented controls (1.06 kg/d). Rice bransupplemented calves were also found to have a greater rate of BW gain compared to nonsupplemented controls in a different investigation (Till et al., 1991).

The performance of beef cattle consuming diets supplemented with rice bran was not better compared to those given corn and soybean hulls (Gadberry et al., 2007). BW and ADG were increased and feed requirement was reduced to $14.5 \%$ when rice bran was fed to finishing Hanwoo steers (Kim et al., 2013a). In another investigation (Kronberg et al., 2011), Angus steers were grazed and fed ground flax seed (FLX, $0.20 \% \mathrm{BW}$ ) or ground corn and soybean meal (CSBM, $0.28 \% \mathrm{BW}$ ) and compared to those fed basal diet (Control). ADG values were 1.04, 1.09, and $0.89 \mathrm{~kg}$ for the FLX, CSBM, and Control groups, respectively $(\mathrm{p}<0.05)$. When grazing steers were given diets supplemented with flax seed, ADG was $0.28 \mathrm{~kg}$ higher than that of the Control group and feed efficiency was better

Table 3. Carcass characteristics of the Hanwoo steers after consuming rice bran, flax seed, and sunflower seed during the finishing period

\begin{tabular}{|c|c|c|c|c|}
\hline & Control $^{1}$ & $\overline{\mathrm{RB}^{2}}$ & $\mathrm{FS}^{3}$ & $\mathrm{SS}^{4}$ \\
\hline No. of heads & 10 & 10 & 9 & 10 \\
\hline Initiation age (mo) & $23.1 \pm 2.4^{12}$ & $21.5 \pm 1.7$ & $21.8 \pm 2.6$ & $22.3 \pm 2.6$ \\
\hline Termination age (mo) & $32.1 \pm 2.4$ & $30.5 \pm 1.7$ & $30.8 \pm 2.6$ & $31.2 \pm 2.6$ \\
\hline \multicolumn{5}{|l|}{ BW (kg) } \\
\hline Initial & $552.8 \pm 35.5$ & $551.2 \pm 33.0$ & $553.8 \pm 34.1$ & $551.2 \pm 33.8$ \\
\hline Final & $768.2 \pm 36.2$ & $785.8 \pm 48.2$ & $786.2 \pm 18.4$ & $789.0 \pm 73.3$ \\
\hline $\mathrm{ADG}(\mathrm{kg})$ & $0.79 \pm 1.00$ & $0.85 \pm 0.94$ & $0.82 \pm 0.11$ & $0.84 \pm 0.19$ \\
\hline Cold carcass wt (kg) & $442.5 \pm 27.9$ & $450.2 \pm 32.6$ & $451.9 \pm 13.3$ & $454.6 \pm 43.4$ \\
\hline \multicolumn{5}{|l|}{ Yield traits } \\
\hline Fat thickness (mm) & $14.2 \pm 4.4^{\mathrm{b}}$ & $14.8 \pm 6.7^{b}$ & $19.8 \pm 4.6^{\mathrm{a}}$ & $15.1 \pm 4.5^{\mathrm{ab}}$ \\
\hline Longissimus muscle area $\left(\mathrm{cm}^{3}\right)$ & $91.2 \pm 10.5$ & $96.4 \pm 5.8$ & $95.9 \pm 6.2$ & $92.4 \pm 8.6$ \\
\hline Yield index & $63.8 \pm 2.8$ & $63.9 \pm 5.0$ & $60.7 \pm 3.4$ & $63.1 \pm 3.8$ \\
\hline Yield grade ${ }^{5}$ & $1.7 \pm 0.5$ & $2.0 \pm 0.7$ & $1.4 \pm 0.5$ & $1.7 \pm 0.7$ \\
\hline \multicolumn{5}{|l|}{ Quality grade } \\
\hline Marbling score ${ }^{6}$ & $5.3 \pm 1.0$ & $4.7 \pm 1.9$ & $4.6 \pm 2.1$ & $5.1 \pm 1.7$ \\
\hline Meat color ${ }^{7}$ & $5.0 \pm 0.0$ & $4.9 \pm 0.3$ & $5.0 \pm 0.0$ & $5.0 \pm 0.5$ \\
\hline Fat color ${ }^{8}$ & $3.0 \pm 0.0$ & $3.0 \pm 0.0$ & $3.0 \pm 0.0$ & $3.0 \pm 0.0$ \\
\hline Texture $^{9}$ & $1.0 \pm 0.0$ & $1.3 \pm 0.5$ & $1.4 \pm 0.5$ & $1.2 \pm 0.4$ \\
\hline Maturity $^{10}$ & $2.3 \pm 0.5$ & $2.1 \pm 0.3$ & $2.0 \pm 0.0$ & $2.0 \pm 0.0$ \\
\hline Quality grade $^{11}$ & $2.4 \pm 0.5$ & $2.1 \pm 1.0$ & $2.0 \pm 1.1$ & $2.2 \pm 0.9$ \\
\hline
\end{tabular}

RB, rice bran; FS, flax seed; SS, sunflower seed; BW, body weight; ADG, average daily gain, SD, standard deviation.

${ }^{1}$ Commercial finishing concentrate. ${ }^{2} 95 \%$ commercial finishing concentrate $+5 \%$ rice bran.

${ }^{3} 95 \%$ commercial finishing concentrate $+5 \%$ flax seed. ${ }^{4} 95 \%$ commercial finishing concentrate $+5 \%$ sunflower seed

${ }^{5}$ Converted into numeric values (grade $\mathrm{A}=3, \mathrm{~B}=2$, and $\mathrm{C}=1$ ).

${ }^{6} 9=$ the most abundant, $1=$ devoid. ${ }^{7} 1=$ bright red, $7=$ dark red. ${ }^{8} 1=$ white, $7=$ yellowish. ${ }^{9} 1=$ fine, $3=$ coarse. ${ }^{10} 1=$ immature, $9=$ mature.

${ }^{11}$ Converted into numeric values $\left(4=\right.$ grade $1^{++}, 3=$ grade $1^{+}, 2=$ grade 1 , and $1=$ grade 2$)$.

${ }^{12}$ Mean \pm SD.

${ }^{\mathrm{ab}}$ Mean values in the same row with different superscript letters are significantly $(\mathrm{p}<0.05)$ different. 
compared to corn-supplemented steers without differences in ADG (Scholljegerdes and Kronberg, 2010). Feeding whole sunflower seeds to finishing steers (Gibb et al., 2004) increased dry matter intake $(\mathrm{p}=0.02)$, ADG $(\mathrm{p}=0.01)$, and gain:feed $(p=0.01)$. Other report has shown that finishing steers fed diet supplemented with sunflower seed did not affect final BW and feed efficiency with reducing dry matter intake $(p=0.005)$ and ADG $(p=0.02)$ (Shah et al., 2006).

\section{Carcass characteristics}

Supplementing RB, FS, and SS to finishing Hanwoo steers resulted in cold carcass weights of $450.2 \pm 32.6$, $451.9 \pm 13.3$, and $454.6 \pm 43.4 \mathrm{~kg}$, respectively ( $\mathrm{p}>0.05$; Table $3)$. Fat thickness of the FS group $(19.78 \pm 4.60 \mathrm{~mm})$ was greater $(p<0.05)$ than that of the other groups. LM area of the RB, FS, SS, and Control groups was $96.4 \pm 5.8,95.9 \pm 6.2$, $92.4 \pm 8.6$, and $91.2 \pm 10.5 \mathrm{~cm}^{2}$, respectively. Final yield grade converted into numerical values considering cold carcass weight, fat thickness, and LM area of the steers was $2.0 \pm 0.7$ for the RB group, $1.7 \pm 0.5$ for the Control animals, $1.7 \pm 0.7$ for the SS group, and $1.4 \pm 0.5$ for the FS cattle. Marbling degree values for the Control, SS, RB, and FS groups were $5.3 \pm 0.9, \quad 5.1 \pm 1.7, \quad 4.7 \pm 1.9$, and $4.6 \pm 2.1$, respectively ( $>0.05)$. Meat color and fat color among the treatment groups were not affected by dietary treatment. Carcass texture ( $1=$ fine, 3 = coarse) was in the order of FS, RB, SS, and Control group $(\mathrm{p}<0.05)$ and the Control group had the highest $(\mathrm{p}<0.05)$ scores in maturity $(1=$ immature, $9=$ mature). Final carcass quality grades converted into numeric values $\left(4=\right.$ grade $1^{++}, 3=$ grade $1^{+}, 2=$ grade 1 , and 1 = grade 2 ) based on marbling degree, meat color, fat color, texture, and maturity were in the order of Control, SS, $R B$ and FS group without differences observed ( $p>0.05$ ).

In a previous study, fat thickness and LM area were not different when finishing steers were fed hay and $0.38 \%$ or $0.76 \% \mathrm{BW}$ of rice bran for $84 \mathrm{~d}$ compared to the Control or corn-fed groups (Forster et al., 1993). Kim et al. (2013a) reported that supplementing the diets of finishing Hanwoo steers with rice bran results in cold carcass weight of 470.0 $\mathrm{kg}$, which was heavier than that of Control animals. However, no differences in fat thickness, LM area, or marbling degree were observed. Kronberg et al. (2011) discovered that there were no changes in hot carcass weight, LM area, fat thickness, or marbling degree when Angus steers were fed a control diet, flax seed $(0.2 \% \mathrm{BW})$, ground corn, and soybean meat $(0.3 \% \mathrm{BW})$ for $85 \mathrm{~d}$. The inclusion of flax in the diets of finishing beef heifers did not affect ( $p$ $=0.32$ ) fat thickness over the 12th rib (Maddock et al., 2006a). Shah et al. (2006) reported that the fat depth of steers fed diets containing sunflower seed was reduced $(\mathrm{p}=$ 0.02 ) to 13.8 from $17.0 \mathrm{~mm}$.

\section{Fatty acid composition}

When Hanwoo steers were fed diet supplemented with rice bran, flax seed, and sunflower seed during the finishing period, percentages of myristic acid $\left(\mathrm{C}_{14: 0}\right)$ in the $\mathrm{LM}$ increased $(p<0.05)$ compared to the Control group. However, palmitic acid $\left(\mathrm{C}_{16: 0}\right)$, stearic acid $\left(\mathrm{C}_{18: 0}\right)$, and arachidic acid $\left(\mathrm{C}_{20: 0}\right)$ percentages were unaffected (Table 4$)$. Among the MUFAs, palmitoleic acid $\left(\mathrm{C}_{16: 1}\right)$ concentrations were higher $(\mathrm{p}<0.05)$ in the SS animals than the Control group. The level of oleic acid $\left(\mathrm{C}_{18: 1}\right)$ was highest $(\mathrm{p}<0.05)$ in the Control group $(47.7 \% \pm 2.7 \%)$ compared to the RB, FS, and SS groups. Additionally, the concentration of linolenic acid $\left(\mathrm{C}_{18: 3}\right)$, a PUFA belonging to the $\mathrm{n}-3$ family, was 2.3 times higher $(p<0.05)$ in the FS group compared to the other groups. The level of total SFAs in the RB group was $45.4 \% \pm 1.9 \%$, the highest $(\mathrm{p}<0.05)$ among the treatment groups. The concentration of total unsaturated fatty acids (UFAs) and total MUFAs in the Control group was $57.1 \% \pm 2.1 \%$ and $53.7 \% \pm 2.3 \%$, respectively, and were the highest values among the groups. There were no differences in total PUFA levels among the treatment groups although LM from the FS group had a high concentration of linolenic acid $\left(\mathrm{C}_{18: 3}\right)$.

Previously, Kim et al. (2011) reported that there were no changes in myristic acid $\left(\mathrm{C}_{14: 0}\right)$, palmitic acid $\left(\mathrm{C}_{16: 0}\right)$, stearic acid $\left(\mathrm{C}_{18: 0}\right)$, or oleic acid $\left(\mathrm{C}_{18: 1}\right)$ percentages in $\mathrm{LM}$ of Hanwoo steers fed rice bran $(0.1 \%$ of concentrate) for $314 \mathrm{~d}$. Additionally, feeding rice bran had no effects on the percentages of conjugated linoleic acid (CLA) or trans vaccenic acid in the LM of finishing Hanwoo steers. In a different study, no differences $(p>0.22)$ were observed in the concentrations of myristic acid $\left(\mathrm{C}_{14: 0}\right)$, palmitic acid $\left(\mathrm{C}_{16: 0}\right)$, stearic acid $\left(\mathrm{C}_{18: 0}\right)$, or total SFAs in the LM of flax seed-fed steers (Kronberg et al., 2011). Intake of flax seed can result in red meat with an increased concentration of beneficial n-3 fatty acids (Maddock et al., 2006b). Meat from cattle fed flax has been reported to contain higher levels of omega-3 fatty acids (Drouillard et al., 2004). However, feeding flax at a concentration of $8 \%$ of the finishing diet does not improve the fatty acid profile of steers (Maddock et al., 2003). Intake of sunflower seed decreased $(\mathrm{p}<0.05)$ palmitic acid $\left(\mathrm{C}_{16: 0}\right)$ and linolenic acid $\left(\mathrm{C}_{18: 3}\right)$ levels with increasing $(\mathrm{p}=0.05)$ the prevalence of oleic acid $\left(\mathrm{C}_{18: 1}\right)$, linoleic acid $\left(\mathrm{C}_{18: 2}\right)$, cis-9, trans-11 CLA, and trans-10, cis-12 CLA in subcutaneous fat (Gibb et al., 2004).

\section{Free amino acid and peptide contents}

No change on levels of alanine (Ala), glycine (Gly), serine (Ser), threonine (Thr), lysine (Lys), arginine (Arg), histidine (His), isoleucine (Ile), leucine (Leu), phenylalanine (Phe), valine (Val), or aspartic acid (Asp) was observed in the LM of Hanwoo steers fed rice bran, flax 
Table 4. Fatty acid composition of longissimus muscle of Hanwoo steers after consuming rice bran, flax seed, and sunflower seed during the finishing period

\begin{tabular}{|c|c|c|c|c|}
\hline & Control $^{1}$ & $\overline{\mathrm{RB}^{2}}$ & $\mathrm{FS}^{3}$ & $\mathrm{SS}^{4}$ \\
\hline & & 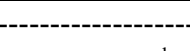 & -1 & 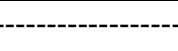 \\
\hline $\mathrm{C}_{10: 0}$ & $0.11 \pm 0.04^{5, \mathrm{~b}}$ & $0.21 \pm 0.10^{\mathrm{ab}}$ & $0.17 \pm 0.06^{\mathrm{ab}}$ & $0.23 \pm 0.19^{\mathrm{a}}$ \\
\hline $\mathrm{C}_{12: 0}$ & $0.18 \pm 0.06$ & $0.20 \pm 0.04$ & $0.22 \pm 0.07$ & $0.22 \pm 0.05$ \\
\hline $\mathrm{C}_{14: 0}$ & $4.00 \pm 0.58^{\mathrm{b}}$ & $4.96 \pm 0.93^{\mathrm{a}}$ & $4.89 \pm 0.65^{\mathrm{a}}$ & $5.06 \pm 1.42^{\mathrm{a}}$ \\
\hline $\mathrm{C}_{14: 1}$ & $0.24 \pm 0.05$ & $0.27 \pm 0.05$ & $0.30 \pm 0.06$ & $0.30 \pm 0.10$ \\
\hline $\mathrm{C}_{16: 0}$ & $28.27 \pm 1.74$ & $29.92 \pm 1.35$ & $28.86 \pm 1.79$ & $29.08 \pm 1.97$ \\
\hline $\mathrm{C}_{16: 1}$ & $5.55 \pm 0.66^{\mathrm{b}}$ & $6.46 \pm 1.15^{\mathrm{ab}}$ & $6.24 \pm 1.25^{\mathrm{ab}}$ & $6.91 \pm 1.19^{\mathrm{a}}$ \\
\hline $\mathrm{C}_{18: 0}$ & $10.30 \pm 0.97$ & $10.21 \pm 1.45$ & $10.19 \pm 1.24$ & $10.14 \pm 1.25$ \\
\hline $\mathrm{C}_{18: 1}$ & $47.73 \pm 2.66^{\mathrm{a}}$ & $44.25 \pm 1.49^{\mathrm{b}}$ & $45.52 \pm 1.82^{\mathrm{b}}$ & $44.69 \pm 2.83^{\mathrm{b}}$ \\
\hline $\mathrm{C}_{18: 2}$ & $2.76 \pm 0.50$ & $2.67 \pm 0.57$ & $2.46 \pm 0.56$ & $2.58 \pm 0.31$ \\
\hline $\mathrm{C}_{18: 3}$ & $0.34 \pm 0.07^{\mathrm{b}}$ & $0.32 \pm 0.13^{\mathrm{b}}$ & $0.75 \pm 0.16^{\mathrm{a}}$ & $0.33 \pm 0.15^{\mathrm{b}}$ \\
\hline $\mathrm{C}_{20: 0}$ & $0.08 \pm 0.03$ & $0.08 \pm 0.03$ & $0.09 \pm 0.06$ & $0.09 \pm 0.04$ \\
\hline $\mathrm{C}_{20: 1}$ & $0.15 \pm 0.09$ & $0.16 \pm 0.07$ & $0.12 \pm 0.08$ & $0.12 \pm 0.09$ \\
\hline $\mathrm{C}_{20: 4}$ & $0.29 \pm 0.07$ & $0.30 \pm 0.14$ & $0.20 \pm 0.14$ & $0.27 \pm 0.11$ \\
\hline SFA & $42.83 \pm 2.09^{b}$ & $45.37 \pm 1.87^{\mathrm{a}}$ & $44.25 \pm 2.42^{\mathrm{ab}}$ & $44.58 \pm 2.33^{\mathrm{ab}}$ \\
\hline UFA & $57.06 \pm 2.11^{\mathrm{a}}$ & $54.42 \pm 1.90^{\mathrm{b}}$ & $55.58 \pm 2.41^{\mathrm{ab}}$ & $55.19 \pm 2.23^{\mathrm{ab}}$ \\
\hline MUFA & $53.67 \pm 2.36^{\mathrm{a}}$ & $51.14 \pm 1.46^{\mathrm{b}}$ & $52.18 \pm 2.07^{\mathrm{ab}}$ & $52.02 \pm 2.14^{\mathrm{ab}}$ \\
\hline PUFA & $3.39 \pm 0.55$ & $3.28 \pm 0.65$ & $3.40 \pm 0.77$ & $3.17 \pm 0.44$ \\
\hline $\mathrm{U} / \mathrm{S}$ & $1.34 \pm 0.12$ & $1.20 \pm 0.09$ & $1.26 \pm 0.13$ & $1.24 \pm 0.11$ \\
\hline $\mathrm{M} / \mathrm{S}$ & $1.26 \pm 0.12$ & $1.13 \pm 0.08$ & $1.18 \pm 0.11$ & $1.17 \pm 0.11$ \\
\hline $\mathrm{P} / \mathrm{S}$ & $0.08 \pm 0.01$ & $0.07 \pm 0.02$ & $0.08 \pm 0.02$ & $0.07 \pm 0.01$ \\
\hline $\mathrm{FI}^{6}$ & $1.17 \pm 0.12^{\mathrm{a}}$ & $1.05 \pm 0.06^{\mathrm{b}}$ & $1.10 \pm 0.09^{\mathrm{ab}}$ & $1.09 \pm 0.09^{\mathrm{ab}}$ \\
\hline
\end{tabular}

RB, rice bran; FS, flax seed; SS, sunflower seed; SFA, saturated fatty acid; UFA, unsaturated fatty acid; MUFA, monounsaturated fatty acid; PUFA, polyunsaturated fatty acid; U/S, unsaturated fatty acid/saturated fatty acid; M/S, monounsaturated fatty acid/saturated fatty acid; $\mathrm{P} / \mathrm{S}$, polyunsaturated fatty acid/saturated fatty acid; FI, flavor index, SD, standard deviation.

${ }^{1}$ Commercial finishing concentrate. ${ }^{2} 95 \%$ commercial finishing concentrate $+5 \%$ rice bran.

${ }^{3} 95 \%$ commercial finishing concentrate $+5 \%$ flax seed. ${ }^{4} 95 \%$ commercial finishing concentrate $+5 \%$ sunflower seed.

${ }^{5} \mathrm{Mean} \pm \mathrm{SD}$.

${ }^{6}$ FI (flavor index $)=\left(\mathrm{C}_{14: 1}+\mathrm{C}_{16: 1}+\mathrm{C}_{18: 1}\right) /\left(\mathrm{C}_{14: 0}+\mathrm{C}_{16: 0}+\mathrm{C}_{18: 0}+\mathrm{C}_{18: 2}\right)$.

${ }^{\mathrm{abc}}$ Mean values in the same row with different superscript letters are significantly $(\mathrm{p}<0.05)$ different.

seed, and sunflower seed during the finishing period (Table $5)$. The concentration of methionine (Met), a sulfurcontaining amino acid, was higher $(\mathrm{p}<0.05)$ in the FS and $\mathrm{SS}$ groups than the Control and RB steers. The level of methionine in the FS group $(1.67 \pm 0.41 \mathrm{mg} / 100 \mathrm{~g})$ was even higher $(\mathrm{p}<0.05)$ than that found in the SS group $(1.17 \pm 0.30$ $\mathrm{mg} / 100 \mathrm{~g}$ ). Glutamic acid (Glu), known to have a positive relationship with beef taste, and tyrosine (Tyr) contents were remarkably elevated $(\mathrm{p}<0.05)$ in the FS group compared to the other steers. Alpha-aminoadipic acid $(\alpha-$ AAA) contents in the FS group were higher $(\mathrm{p}<0.05)$ than levels in the Control, RB, or SS group. Additionally, anserine (Ans) and carnosine (Car) concentrations was numerically higher $(\mathrm{p}>0.05)$ in the FS steers relative to the other groups.

Beef flavor, which develops during heating process, depends on the amount and proportion of precursor compounds present. Among various components of meat, proteins, lipids, and carbohydrates play key roles in the development of flavor since they are capable of developing into important flavor precursors when heat applied
(Mottram, 1998).

\section{Sensory evaluation results}

According to sensory evaluation, tenderness $(5.7 \pm 0.3)$ and juiciness $(5.5 \pm 0.3)$ scores were the highest in RB group whereas flavor (5.6 \pm 0.6$)$, umami $(5.5 \pm 0.5)$, and overall palatability $(5.5 \pm 0.4)$ scores were the highest in FS group without statistical significance $(p>0.05)$ (Table 6).

Recent consumer research has shown that once tenderness is within an acceptable range or when variation in tenderness has been minimized, flavor becomes the most important determinant for beef consumers' assessments of overall satisfaction (Killinger et al., 2004). Flavor results from the combination of basic tastes (sweet, sour, bitter, salt, and umami) derived from water-soluble compounds and odors produced from a myriad of substances present in the food product from the onset or via various reactions (Farmer and Mottram, 1994). The flavors and aromas associated with beef are generally those that develop during heating. When water-soluble substances produced from precursor compounds dissolve in saliva, they bind to the 
Table 5. Free amino acid and peptide contents in longissimus muscle of Hanwoo steers fed rice bran, flax seed, and sunflower seed during the finishing period

\begin{tabular}{lrrrr}
\hline & Control $^{1}$ & RB $^{2}$ & FS $^{3}$ & SS $^{4}$ \\
Ala & $23.82 \pm 6.75^{5}$ & $23.46 \pm 4.40$ & $26.29 \pm 3.54$ & $23.12 \pm 3.89$ \\
Gly & $5.91 \pm 1.57$ & $5.39 \pm 1.21$ & $6.04 \pm 1.09$ & $5.86 \pm 0.89$ \\
Ser & $2.99 \pm 1.06$ & $3.03 \pm 0.84$ & $3.08 \pm 1.33$ & $2.61 \pm 0.39$ \\
Thr & $3.14 \pm 1.18$ & $3.19 \pm 0.98$ & $2.80 \pm 0.59$ & $2.45 \pm 0.41$ \\
Lys & $4.29 \pm 1.65$ & $4.22 \pm 1.92$ & $4.27 \pm 1.04$ & $4.17 \pm 0.63$ \\
Arg & $4.33 \pm 1.56$ & $4.74 \pm 1.11$ & $4.55 \pm 1.15$ & $3.92 \pm 0.67$ \\
His & $2.53 \pm 0.78$ & $2.46 \pm 0.44$ & $2.66 \pm 0.41$ & $2.42 \pm 0.47$ \\
Ile & $2.66 \pm 1.02$ & $2.67 \pm 0.66$ & $2.79 \pm 0.51$ & $2.42 \pm 0.45$ \\
Leu & $4.57 \pm 1.92$ & $4.68 \pm 1.43$ & $5.06 \pm 1.10$ & $4.01 \pm 0.84$ \\
Met & $0.56 \pm 0.42^{\mathrm{b}}$ & $0.45 \pm 0.71^{\mathrm{b}}$ & $1.67 \pm 0.41^{\mathrm{a}}$ & $1.17 \pm 0.30^{\mathrm{a}}$ \\
Phe & $2.90 \pm 1.06$ & $2.93 \pm 0.89$ & $3.23 \pm 0.64$ & $2.50 \pm 0.46$ \\
Val & $3.39 \pm 1.24$ & $3.35 \pm 0.70$ & $3.62 \pm 0.71$ & $3.28 \pm 0.60$ \\
Asp & $0.30 \pm 0.15$ & $0.30 \pm 0.09$ & $0.13 \pm 0.20$ & $0.26 \pm 0.23$ \\
Glu & $2.39 \pm 1.09^{\mathrm{b}}$ & $3.00 \pm 1.40^{\mathrm{b}}$ & $4.58 \pm 1.96^{\mathrm{a}}$ & $2.38 \pm 0.96^{\mathrm{b}}$ \\
Tau & $21.40 \pm 4.95$ & $26.55 \pm 5.27$ & $26.96 \pm 7.47$ & $25.18 \pm 8.54$ \\
Tyr & $2.91 \pm 1.18^{\mathrm{ab}}$ & $2.86 \pm 0.90^{\mathrm{ab}}$ & $3.26 \pm 0.75^{\mathrm{a}}$ & $2.39 \pm 0.47^{\mathrm{b}}$ \\
$\alpha$-AAA & $0.00 \pm 0.00^{\mathrm{b}}$ & $0.10 \pm 0.22^{\mathrm{b}}$ & $0.53 \pm 0.27^{\mathrm{a}}$ & $0.07 \pm 0.12^{\mathrm{b}}$
\end{tabular}

RB, rice bran; FS, flax seed; SS, sunflower seed; $\alpha$-AAA, $\alpha$-amino aminoadipic acid; SD, standard deviation.

${ }^{1}$ Commercial finishing concentrate. ${ }^{2} 95 \%$ commercial finishing concentrate $+5 \%$ rice bran.

${ }^{3} 95 \%$ commercial finishing concentrate $+5 \%$ flax seed. ${ }^{4} 95 \%$ commercial finishing concentrate $+5 \%$ sunflower seed.

${ }^{5}$ Mean \pm SD.

${ }^{\text {abc }}$ Mean values in the same row with different superscript letters are significantly $(\mathrm{p}<0.05)$ different.

taste buds and stimulate responses that are perceived in the brain. Odors are generated when volatile compounds bind to receptors in the olfactory bulb behind the nasal cavity and stimulate a response.

Intake of rice bran and rice oil for $126 \mathrm{~d}$ by feedlotfinished steers was found to improve tenderness $(p=0.81)$, juiciness $(p=0.33)$, and palatability $(p=0.22)$ of steaks extracted from the LM between the 10th and 12th ribs (Donicht et al., 2011). When finishing Hanwoo steers were fed rice bran for $314 \mathrm{~d}$, juiciness and overall palatability of the LM muscle was improved $(\mathrm{p}<0.05)$ compared to the Control animals (Kim et al., 2011). An early study by Bowling et al. (1977) comparing forage-finished and grainfinished beef suggested that the consumer or retailer may discriminate against forage-finished beef due to the color (muscle or fat) and palatability (flavor, tenderness, or both) of the meat.

When yearling beef heifers were fed feedlot diets that

Table 6. Sensory evaluations for longissimus muscle of Hanwoo steers fed rice bran, flax seed, and sunflower seed during the finishing period

\begin{tabular}{lcccc}
\hline & Control $^{1}$ & RB $^{2}$ & FS $^{3}$ & SS $^{4}$ \\
\hline Tenderness $^{5}$ & $5.50 \pm 0.84^{11}$ & $5.67 \pm 0.32$ & $5.25 \pm 0.49$ & $5.10 \pm 0.85$ \\
Juiciness $^{6}$ & $5.08 \pm 0.65$ & $5.50 \pm 0.26$ & $5.20 \pm 0.00$ & $5.35 \pm 0.78$ \\
Flavor $^{7}$ & $5.25 \pm 0.78$ & $5.40 \pm 0.50$ & $5.60 \pm 0.57$ & $5.45 \pm 0.07$ \\
Umami $^{8}$ & $5.00 \pm 0.53$ & $5.07 \pm 0.31$ & $5.55 \pm 0.49$ & $5.10 \pm 0.42$ \\
Oiliness $^{9}$ & $5.10 \pm 0.68$ & $5.40 \pm 0.53$ & $5.15 \pm 0.21$ & $5.35 \pm 0.92$ \\
Overall palatability $^{10}$ & $4.95 \pm 0.70$ & $5.23 \pm 0.38$ & $5.50 \pm 0.42$ & $5.05 \pm 0.35$ \\
\hline
\end{tabular}

RB, rice bran; FS, flax seed; SS, sunflower seed; SD, standard deviation.

${ }^{1}$ Commercial finishing concentrate. ${ }^{2} 95 \%$ commercial finishing concentrate $+5 \%$ rice bran.

${ }^{3} 95 \%$ commercial finishing concentrate $+5 \%$ flax seed. ${ }^{4} 95 \%$ commercial finishing concentrate $+5 \%$ sunflower seed.

${ }^{5} 1=$ extremely tough, $8=$ extremely tender. ${ }^{6} 1=$ extremely dry, $8=$ extremely juicy.

${ }^{7} 1=$ extremely unflavorful, $8=$ extremely flavorful. ${ }^{8} 1=$ extremely absent, $8=$ extremely present.

${ }^{9} 1=$ extremely dry, $8=$ extremely oily. ${ }^{10} 1=$ extremely bad, $8=$ extremely good.

${ }^{11}$ Mean \pm SD. 
contained no flax, whole flax, rolled flax, or ground flax, the sensory panel tenderness ratings $(p=0.44)$, flavor ratings $(p=0.35$ ), and Warner-Bratzler shear force (WBSF; $\mathrm{p}=0.06$ ) were unaffected (Maddock et al., 2006b). Maddock et al. (2003) reported that steaks from flax-fed steers were less juicy and tender than steaks from steers finished on a corn-based control diet. Drouillard et al. (2004) did not note any differences in sensory traits or shear force among steers and heifers fed different concentrations of flax or Holstein steers fed 5\% flax. Supplementation with ground flax seed did not change ( $>0.12)$ WBSF measurements for steaks from the grazing steers, nor did this diet influence $(\mathrm{p}>0.29)$ the tenderness, juiciness, or flavor intensity of the meat. However, there appeared to be differences $(p=0.04)$ in sensory perception of the off-flavor intensity for steaks from flax seed-fed steers. Panelists sensed a slightly more intense off-flavor in steaks from steers fed flax seed compared to steaks from steers fed the control diet $(p=0.07)$. The off-flavor intensity ratings for steaks from steers fed flax seed may be related to greater concentrations of linolenic acid $\left(\mathrm{C}_{18: 3}\right)$ (Kronberg et al., 2011).

Addition of SS that contain high oleic acid levels to corn diets increased $(p=0.02)$ juiciness whereas highlinoleic acid SS elevated initial and overall tenderness $(\mathrm{p}=$ 0.02) of LM steaks from steers (Shah et al., 2006). Mir et al. (2003) noted that tenderness scores tended to increase compared to those for vitamin E-supplemented steers when sunflower oil containing about $70 \%$ linoleic acid $\left(\mathrm{C}_{18: 2}\right)$ is fed to finishing steers. Duckett et al. (2001) reported similar results for meat from high oil containing corn-fed steers and suggested that the cause of differences in flavor may be related to the fatty acid composition of the meat.

In conclusion, supplementation of flax seed to the concentrates of finishing Hanwoo steers tended to improve ( $>0.05$ ) flavor, umami, and overall palatability of LM. These results might be caused by increases in the concentration of free amino acids, glutamic acid, methionine, and $\alpha$-AAA, and peptides, anserine and carnosine, and their complex reactions. Further detailed studies, however, to understand mechanisms for the improved beef flavors by feeding flax seed in the diet of finishing beef cattle are necessary.

\section{CONFLICT OF INTEREST}

We certify that there is no conflict of interest with any financial organization regarding the material discussed in the manuscript.

\section{ACKNOWLEDGMENTS}

The authors gratefully acknowledge the financial support (2010) of Woosung Feed Co., Ltd. This study was also supported by a 2014 Yeungnam University research grant (214A061048).

\section{REFERENCES}

Bowling, R. A., G. C. Smith, Z. L. Carpenter, T. R. Dutson, and W. M. Oliver. 1977. Comparison of forage-finished and grainfinished beef carcasses. J. Anim. Sci. 45:209-215.

Donicht, P. A. M. M., J. Restle, L. Da S. Freitas, A. M. Callegaro, M. S. Weise, and I. L. Brondani. 2011. Fat sources in diets for feedlot-finished steers - carcass and meat characteristics. Ciência Anim. Bras. 12:487-496.

Drouillard, J. S., M. A. Seyfert, E. J. Good, E. R. Loe, B. Depenbusch, and R. Daubert. 2004. Flaxseed for finishing beef cattle: Effects on animal performance, carcass quality, and meat composition. Plant Sci. 55:149-159.

Duckett, S. K., B. A. Jardner, M. A. Winds, and F. N. Owen. 2001. Impact of high oil corn on beef steak quality. J. Anim. Sci.(Suppl.). 78:155.

Due, A., T. M. Larsen, K. Hermansen, S. Stender, J. J. Holst, S. Toubro, and A. Astrup. 2008. Comparison of the effects on insulin resistance and glucose tolerance of 6-mo highmonounsaturated-fat, low-fat, and control diets. Am. J. Clin. Nutr. 87:855-862.

Farmer, L. J. and D. S. Mottram. 1994. Lipid-Maillard interactions in the formation of volatile aroma compounds. J. Article 35: 313-326.

Folch, J., M. Lees, and G. H. Sloane Stanley. 1957. A simple method for the isolation and purification of total lipides from animal tissues. J. Biol. Chem. 226:497-509.

Forster, L. A. Jr., A. L. Goetsch, D. L. Sr. Galloway, and Z. B. Johnson. 1993. Feed intake, digestibility, and live weight gain by cattle consuming forage supplemented with rice brand and (or) corn. J. Anim. Sci. 71:3105-3014.

Gadberry, M. S., P. A. Beck, and S. A. Gunter. 2007. Review: Rice milling coproducts as feedstuffs for beef cattle. The Prof. Anim. Sci. 23:309-315.

Gibb, D. J., F. N. Owens, P. S. Mir, Z. Mir, M. Ivan, and T. A. McAllister. 2004. Value of sunflower seed in finishing diets of feedlot cattle. J. Anim. Sci. 82:2679-2692.

Gillingham, L. G., S. Harris-Janz, and P. J. Jones. 2011. Dietary monounsaturated fatty acids are protective against metabolic syndrome and cardiovascular disease risk factors. Lipids 46:209-228.

Henderson, J. W., R. D. Ricker, B. A. Bidlingmeyer, and C.Woodward. 2000. Rapid, accurate, sensitive, and reproducible HPLC analysis of amino acids. Agilent Technologies Technical Note 5980-1193E.

Killinger, K. M., C. R. Calkins, W. J. Umberger, D. M. Feuz, and K. M. Eskridge. 2004. A comparison of consumer sensory acceptance and value of domestic beef steaks and steaks from a branded, Argentine beef program. J. Anim. Sci. 82:33023307.

Kim, S. I., K. K. Jung, D.Y. Kim, J. Y. Kim, and C. B. Choi. 2011. Effects of supplementation of rice bran and roasted soybean in the diet on physico-chemical and sensory characteristics of M. longissimus dorsi of Hanwoo steers. Korean J. Food Sci. Anim. 
Resour. 31:451-459.

Kim, S. I., G. H. Lee, and C. B. Choi. 2013a. Effects of supplementary rice bran and roasted soybean in the diets on carcass characteristics and composition of CLA in Hanwoo steers. J. Anim. Sci. Technol. 55:435-442.

Kim, S. I., B. R. Cho, and C. B. Choi. 2013b. Effects of sesame meal on growth performances and fatty acid composition, free amino acid contents, and panel tests of loin of Hanwoo steers. J. Anim. Sci. Tech. 55:451-460.

Kris-Etherton, P. M., T. A. Pearson, Y. Wan, R. L. Hargrove, K. Moriarty, V. Fishell, and T. D. Etherton. 1999. Highmonounsaturated fatty acid diets lower both plasma cholesterol and triacylglycerol concentrations. Am. J. Clin. Nutr. 70:10091015.

Kronberg, S. L., E. J. Scholljegerdes, A. N. Lepper, and E. P. Berg. 2011. The effect of flaxseed supplementation on growth, carcass characteristics, fatty acid profile, retail shelf life, and sensory characteristics of beef from steers finished on grasslands of the northern Great Plains. J. Anim. Sci. 89:28922903.

Korean Beef Carcass Grading Standard. 2014. Korean Standards for Grading Animal Products. Ministry of Agriculture, Food and Rural Affairs, Jeonju, Korea.

Lepage, G. and C. C. Roy. 1986. Direct transesterification of all classes of lipids in a one-step reaction. J. Lipid Res. 27:114120.

Maddock, T. D., V. L. Anderson, P. T. Berg, R. J. Maddock, and M. J. Marchello. 2003. Influence of level of flaxseed addition and time fed flaxseed on carcass characteristics, sensory panel evaluation and fatty acid content of fresh beef. Proc. 56th Recip. Meats Conf. 56:110 (Abstr.)

Maddock, T. D., M. L. Bauer, K. B. Koch, V. L. Anderson, R. J. Maddock, G. Barceló-Coblijn, E. J. Murphy, and G. P. Lardy. 2006a. Effect of processing flax in beef feedlot diets on performance, carcass characteristics, and trained sensory panel ratings. J. Anim. Sci. 84:1544-1551.

Maddock, T. D., B. Kreft, R. J. Maddock, V. L. Anderson, and G. P. Lardy. 2006b. Effect of including flax in beef creep feed on performance and subsequent carcass characteristics. J. Anim. Vet. Adv. 5:156-160.
Mir, P. S., T. A. McAllister, S. Zaman, S. D. Morgan Jones, M. L. He, J. L. Aalhus, L. E. Jeremiah, L. A. Goonewardene, R. J. Weselake, Z. Mir. 2003. Effect of dietary sunflower oil and vitamin $\mathrm{E}$ on Beef cattle performance, carcass characteristics and meat quality. Can. J. Anim. Sci. 83:53-66.

Mottram, D. S. 1998. Flavour formation in meat and meat products: A review. Food Chem. 62:415-424.

National Live Stock and Meat Board. 1995. Research guidelines for cookery, sensory evaluation, and instrumental tenderness measurements of meat. American Meat Science Association, Champaign, IL, USA.

Rasmussen, B. M., B. Vessby, M. Uusitupa, L. Berglund, E. Pedersen, G. Riccardi, A. A. Rivellese, L. Tapsell, and K. Hermansen. 2006. Effects of dietary saturated, monounsaturated, and n-3 fatty acids on blood pressure in healthy subjects. Am. J. Clin. Nutr. 83:221-226.

Ritchie, H. 2005. Strategies for managing marbling in beef cattle. Michigan State University. East Lansing, MI, USA.

Scholljegerdes, E. J. and S. L. Kronberg. 2010. Effect of supplemental ground flaxseed fed to beef cattle grazing summer native range on the northern Great Plains. J. Anim. Sci. 71:3199-3205.

Shah, M. A., P. S. Mir, J. L. Aalhus, J. Basarab, and E. K. Okine. 2006. Effects of sunflower seed inclusion in finishing diets for steers on performance, carcass characteristics, muscle and adipose fatty acid composition and meat quality. Can. J. Anim. Sci. 86:37-48.

Smith, S. B., D. K. Lunt, K. Y. Chung, C. B. Choi, R. K. Tume, and M. Zembayashi. 2006. Adiposity, fatty acid composition, and delta-9 desaturase activity during growth in beef cattle. J. Anim. Sci. J. 77:478-486.

SPSS. 2011. SPSS Release Ver. 19.0. SPSS Inc., Chicago, IL, USA.

Till, A. R., M. R. Hunt, T. Panggabean, D. Bulo, and G. J. Blair. 1991. The live weight gain of cattle at pasture in South Sulawesi supplemented with locally available by-products. Asian Australas. J. Anim. Sci. 4:85-90

Whetsell, M. S., E. B. Rayburn, and J. D. Lozier. 2003. Human health effects of fatty acids in beef. Fact Sheet: West Virgina University \& USDA Agriculture. http://www.wvu.edu/ agexten/forglvst/humanhealth.pdf Accessed November 13, 2014. 